\title{
'|||||||||||||||||||||||||||||||||||||||||||||||||||||||||.
}

\section{Ohne Sinn und Verstand}

Liebe Leserin, lieber Leser,

eines der dominanten und kontrovers diskutierten Themen ist seit einiger Zeit die sogenannte Mobilitäts- beziehungsweise Klimawende. Politik, Interessenverbände und auch Fahrzeughersteller überbieten sich geradezu mit Ideen zum Beitrag des Verkehrs zur Klimarettung. Der Dreiteiler von Christiane Köllner auf Springer Professional gibt einen guten Überblick und eine kritische Einordnung.

Niemand, der klar denkt, stellt die Notwendigkeit schneller Maßnahmen zum Klimaschutz infrage. Problematisch ist aber, wenn die Politik physikalische Gesetzmäßigkeiten negiert - „Politik statt Physik“, wie Johannes Winterhagen in seinem Kommentar in faz.net treffend titelte. Noch bedenklicher ist es, wenn sich OEMs mit ihren Zielen für E-Fahrzeuge geradezu überbieten (müssen), um Imageschäden abzuwenden. Kein Ruhmesblatt ist auch das Verhalten vieler Publikumsmedien, die alles „hypen“, was diesem Trend folgt, und jede Gegenstimme infrage stellen.

Wenn Mitgliedsstaaten der EU den Verbrennungsmotor verbieten, ausschließlich auf Batterieantriebe setzen und die Industrie auf diesen Weg zwingen wollen, dann ist das eine staatlich verordnete Verhinderung technologieoffener Entwicklung und der Abschied aus dem Kreis führender Technologienationen. Dem globalen Klima hilft das im Übrigen auch nicht. Wo bitte liegt die physikalische und umweltbezogene Logik, wenn Strom für die Fahrzeugbetankung dreifach, strombasierte Kraftstoffe aus nachhaltigen Quellen aber nur zweifach angerechnet werden dürfen selbst wenn sie dort hergestellt werden, wo dies nachweislich sinnvoll wäre? So wird nur strombasierter Kraftstoff unrentabel gemacht. Und wie soll bitte ein Güterverkehr komplett batterieelektrisch oder per Oberleitung umweltverträglich und wirtschaftlich sinnvoll abgebildet werden? Welchen Sinn - außer dem ideologischen
- hat eine Verhinderung von E-Fuels, die gerade für Nutzfahrzeuge, Bau- und Landmaschinen wichtig wären?

Was wie das Drehbuch zu einem TV-Krimi klingt, ist keine Fiktion, sondern steht im Entwurf des Bundesumweltministeriums zum Gesetz zur Weiterentwicklung der Treibhausgasminderungsquote. Es ist wichtig, fossile Kraftstoffe schnell zu ersetzen, nur macht es keinen Sinn, gegen die Physik und die Märkte mit dem Kopf durch die Wand zu wollen und solch ein Vorgehen als Klimarettung oder goldenen Weg in die Zukunft zu propagieren. Hier wird vielmehr, wie faz.net anmerkt „die Grenze zur Täuschung überschritten“.

Eines ist klar: Ohne Klimaschutz und Mobilität gibt es keine Zukunft. Deshalb müssen alle Maßnahmen international abgestimmt, systemisch angelegt und damit nachhaltig sein. Beherzigen die Entscheider dies nicht, dann handeln sie ohne Sinn und Verstand.

Ich wünsche Ihnen viel Spaß bei der Lektüre der aktuellen ATZheavyduty.

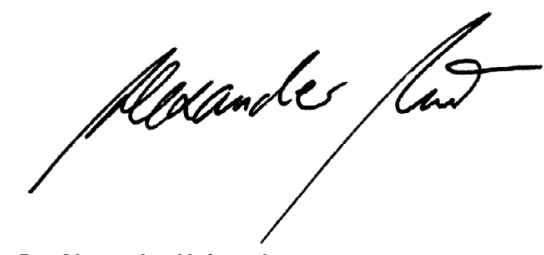

Dr. Alexander Heintzel

Chefredakteur

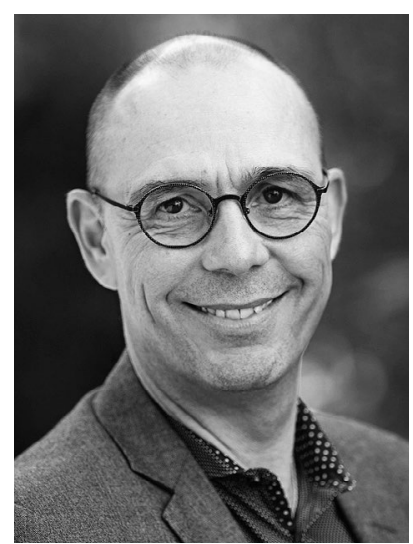

ANTRIEB. EFFIZIENZ. LEISTUNG.

Die Automobilbranche steht vor neuen Herausforderungen - die Mobilitätswende erfordert konsequentes Umdenken und technologieoffenes Entwickeln. Als international führendes technisch-wissenschaftliches Fachmagazin für Entscheider in der Antriebsentwicklung und -produktion versteht sich die MTZ als eine Informationsplattform zukünftiger Antriebe - elektrisch und verbrennungsmotorisch. Die MTZ fördert den Informationstransfer zwischen Herstellern, Zulieferern, Dienstleistern sowie Forschungs- und Entwicklungszentren in aller Welt. Nutzen Sie zusätzlich zu den Printausgaben das interaktive E-Magazin und profitieren Sie von der einzigartigen Wissensdatenbank des Onlinearchivs mit pdf-Download.
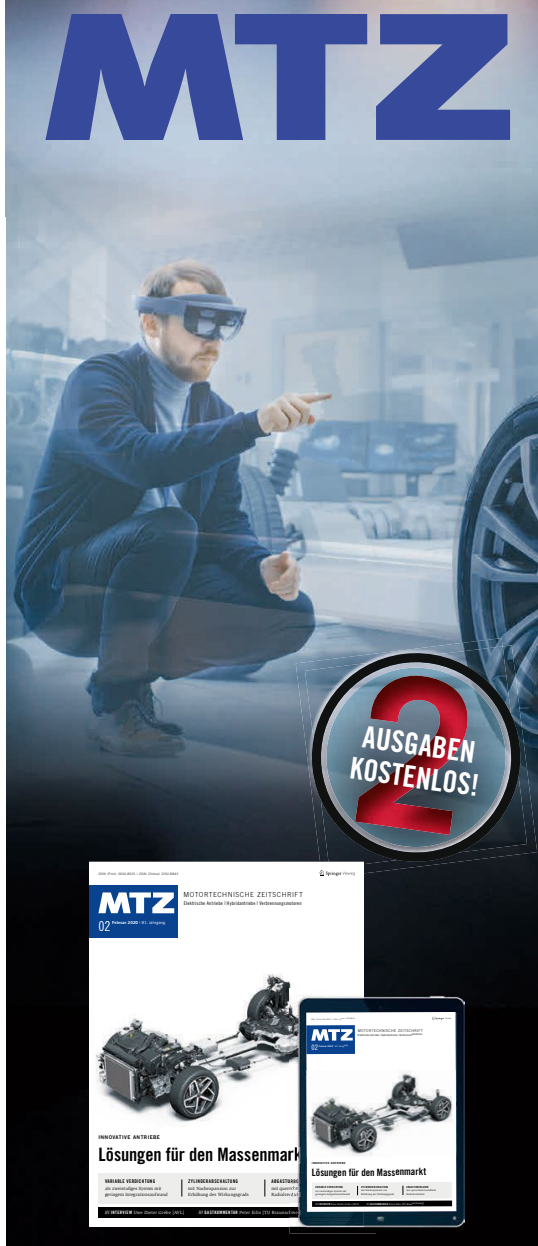

www.mein-fachwissen.de/mtz/probe 